\title{
Invasive carcinomas of the male breast: a morphologic study of the distribution of histologic subtypes and metastatic patterns in 778 cases
}

\author{
Ana M. Burga • Oluwole Fadare • Ruth A. Lininger • \\ Fattaneh A. Tavassoli
}

Received: 30 May 2006 / Accepted: 24 August 2006 / Published online: 13 October 2006

(C) Springer-Verlag 2006

\begin{abstract}
The current investigation was conducted to evaluate the proportional distribution of the various histologic subtypes (including newly recognized variants) of male breast carcinomas, to determine whether any his-
\end{abstract}

The opinions and assertions contained herein are the private views of the authors and are not to be considered official or as necessarily reflecting the opinion of the United States Government or any of its subsidiaries.

A. M. Burga $\cdot$ R. A. Lininger $\cdot$ F. A. Tavassoli

Department of Gynecologic and Breast Pathology,

Armed Forces Institute of Pathology,

Washington, DC, USA

O. Fadare $\cdot$ F. A. Tavassoli

Department of Pathology, Yale University School of Medicine, New Haven, CT, USA

\section{A. M. Burga}

Department of Pathology, Englewood Hospital,

Englewood, NJ, USA

O. Fadare

Department of Pathology, Wilford Hall Medical Center, Lackland Air Force Base,

San Antonio, TX, USA

O. Fadare

Department of Pathology,

University of Texas Health Science Center at San Antonio,

San Antonio, TX, USA

\section{R. A. Lininger}

Department of Pathology, University of North Carolina,

Chapel Hill, NC, USA

O. Fadare $(\square)$

Department of Pathology, Wilford Hall Medical Center,

2200 Bergquist Dr., Ste 1,

Lackland AFB, TX 78236, USA

e-mail: oluwolefadare@yahoo.com tologic subtypes occur with a frequency that is markedly discordant with the expected frequencies from published data on parallel female breast tumors. We also aimed to document the distribution of malignancies metastatic to the breast. Seven hundred fifty-nine archived cases of primary invasive carcinoma involving the male breast were retrieved and subcategorized into histologic subtypes according to contemporary criteria. Six hundred forty-three (84.7\%) tumors were pure infiltrating ductal carcinoma (IDC) not otherwise specified. The most common of the remainder included papillary carcinoma with invasion in the form of IDC $(n=34)$, mixed IDC and mucinous carcinoma $(n=26)$, and pure mucinous carcinoma $(n=21)$. In 19 cases, metastases from other sites involved the breast, most commonly (58\%) cutaneous melanoma. Invasive carcinoma of the male breast appears to display a morphologic spectrum and distribution of histologic subtypes that is comparable to those of the female breast, with some expected variation. Compared with published experience on their female counterparts, there is a two-fold increase in the frequency of invasive papillary carcinoma in the male breast. Finally, the most common tumor metastatic to the male breast in this series was cutaneous melanoma.

Keywords Male $\cdot$ Breast $\cdot$ Carcinoma $\cdot$ Papillary $\cdot$ Cancer

\section{Introduction}

Breast cancer in males is relatively uncommon, with approximately 1,450 newly diagnosed cases annually in the United States, and an associated mortality rate that accounts for less than $0.2 \%$ of all cancer-related deaths in men $[1,4,9,15,17,20,28]$. However, recent epidemiologic studies suggest that the incidence of male breast 
cancer has been steadily increasing [7, 14]. Utilizing data from the National Cancer Institute's Surveillance, Epidemiology and End Results database for the 26-year period between 1973 and 1998, Giordano et al. [7] found that the incidence of male breast cancer increased from 0.86 to 1.08 per 100,000 population. This increasing incidence, in addition to the better elucidation of the role of BRCA2 mutations in male breast cancer, has renewed interest in specifically identifying the underlying pathogenesis of male breast cancer and clarifying the specific differences, if any, between male and female breast cancer.

On a broad demographical level, male and female breast cancers are fundamentally similar with the main differences lying in older age of occurrence and lower incidence of the former. However, significant differences have been noted between male and female breast cancers with respect to the expression of a variety of biologic factors, including hormone receptors such as estrogen receptor, progesterone receptor, c-erbB-2, estrogen-inducible proteins such as $\mathrm{pS} 2$, Cathepsin D, hsp27, proteins related to basement membrane and extracellular matrix degradation such as the urokinase system of plasminogen activation and their inhibitors, and protooncogenes such as bcl-2 [2, 6, 7, 18, 21, 22, $24,27]$. At the morphologic level, male ductal intraepithelial neoplasia (ductal carcinoma in situ), in contrast to similar lesions in females, displays a distinct histologic profile in which the majority of tumors are of the papillary type, with cribriform, micropapillary, and solid types being much less common [13]. In particular, the comedo-type of DIN (comedo DCIS) is notably rare in the male breast [13]. For invasive carcinomas, the female and male tumors are morphologically indistinguishable [26] and many published studies on male breast cancer frequently represent the major histologic subtypes of nonlobular breast carcinoma, such as ductal, medullary, mucinous, and papillary $[3,7,8,12,19$, $22,25]$. However, these studies generally do not have the distribution and relative frequencies of the various histologic subtypes as their main focus, and as such, pathologically important distinctions such as signet ring vs colloid carcinoma (both subsumed under mucin producing carcinoma), or metaplastic carcinoma vs infiltrating duct carcinoma not otherwise specified are not emphasized. Over- or underepresentation of a particular histologic subtype in male breast cancers may provide valuable insight into the etiopathogenetic differences between male and female breast cancers and may provide an important nidus for further studies.

In this study, we investigated the frequencies and distribution of the various histologic subtypes in a large data set of invasive carcinomas seen at a large tertiary center over a 40-year period. Our goals are to document these frequencies and distribution and to see whether any histologic subtypes are notably distinct in frequency of oc- currence in the male breast, as compared with historical published data on similar lesions in the female breast. The frequencies and sites of origin of metastatic tumors to the male breast during the study period were also investigated.

\section{Materials and methods}

After approval from our institutional research review committee, cases of invasive carcinoma involving the male breast diagnosed between 1957 and 1997 were retrieved from the archived institutional files of the Armed Forces Institute of Pathology (AFIP, Washington DC, USA). The available records and slides on each patient were reviewed. All cases with ambiguous gender (even if one among the multiple entries for gender was coded as female rather than male) were excluded $(n=38)$. Diagnostic designations were assigned according to contemporary WHO criteria [23]. All special types of carcinoma inclusive of mucinous, tubular, secretory, adenoid cystic, lobular, metaplastic, etc. $(n=116)$ were reviewed extensively; many of these cases had been evaluated repeatedly as part of various previously published studies from the department and slides of good quality were available on these cases for review. Among the 643 cases of infiltrating duct carcinoma not otherwise specified, only cases with good quality and adequate representative slides $(n=365)$ were graded, using the modified Scarf-Bloom Richardson scoring system. On 78 cases, the slides were so old that we could only confirm the presence of a ductal type carcinoma. The other 200 cases did not have all of the patients' slides pertaining to the lesion available and the final interpretation was based on the descriptions of morphology in the AFIP files. Because cases sent to AFIP are mostly for confirmation of diagnosis, information about therapy beyond what was in the surgical pathology report or the accompanying cover letter are generally not available. Some patients had repeated material sent to AFIP as the lesion recurred, which is how follow-up information was collected in a small subset of cases.

Information about age, operative procedure, nodal excision, and distant metastases were retrieved from the patients' AFIP files. Diagnostic designations were assigned largely based on morphologic and not immunohistochemical features since in many cases there were no blocks or unstained slides available for additional studies. Thirty of these cases were the subject of a previous report [13], which focused on in situ carcinomas and were reported in 1998. Another 113 cases, 8 of which were ductal in situ and another 9 papillary carcinomas, were subject of another report in 1969 [19] Cases of nonhematopoietic or lymphoreticular malignancies metastatic to the male breast during this period were also catalogued. 


\section{Results}

Seven hundred and seventy-eight cases of breast carcinoma were reported as involving the male breast during the study period. Seven hundred fifty-nine of these cases were considered primary to the breast and 19 as metastatic to it. The patients ranged in age from 9 to 94 years (mean 61 years). The age distribution available for 520 cases was as follow: 8 were $\leq 30$ years, 22 were $\leq 40$ years, 205 were 41 to 60 years, 251 were 61 to 80 years, and 34 were over 80 years of age. Among the 490 for whom the racial information was available, 401 were Caucasian, not of Hispanic origin, 82 were Black, not of Hispanic origin, 6 were Asians or Pacific Islander, 1 was Hispanic, and the race was unknown for 269. The carcinomas ranged from $\leq 1 \mathrm{~mm}$ (microinvasive) to $12 \mathrm{~cm}$. Many of the cases with multifocal early invasion of 1 to $7 \mathrm{~mm}$ were associated with large solitary or multifocal papillary intraductal carcinomas. The various histologic subtypes and their proportional distribution are outlined in Table 1, whereas representative images are illustrated in Fig. 1. Pure infiltrating duct carcinoma not otherwise specified was the most common histologic subtype, representing $84.7 \%$ of all cases. Six hundred forty-three cases were in the latter group, including 34 cases associated with Paget's disease, 17 cases with prominent apocrine features in $<50 \%$ of tumor volume (i.e., insufficient to qualify as apocrine carcinomas), 4 cases with prominent medullary features (tumor circumscription, cellular syncytia, sparse lymphocytic infiltrate), 2 cases of infiltrating duct carcinoma with signet ring cells $(<5 \%$ of tumor volume), 3 cases of infiltrating duct carcinoma with focal clear cells ( $<5 \%$ of tumor volume), and 3 cases of carcinoma with osteoclast-like giant cells. Papillary intraductal carcinoma with invasion in the form of infiltrating duct carcinoma represented 4.5\% (34/759 each) of all cases. Other well-represented histologic subtypes or combinations included mixed mucinous and infiltrating duct carcinoma ( $n=26,3.4 \%)$, pure mucinous carcinoma $(21,2.8 \%)$, and adenoid cystic carcinoma $(n=8,1.05 \%)$. Other variants each constituted less than $1 \%$ of all cases (Table 1). Notably, there were three cases of lobular carcinoma. As noted previously, these diagnoses were not based on immunohistochemical confirmation by immunostain for E-cadherin, but all three showed archetypal morphologic features of lobular carcinoma with loosely cohesive single cell files and rare intracytoplasmic lumens. Two of these cases had evidence of lobular development in the surrounding breast but the slides available for review did not show lobular intraepithelial neoplasia (LIN). There were also three cases of mixed lobular and ductal carcinomas, in which these areas were spatially separate. The youngest patient, a 9year-old boy was the only one with pure secretory carcinoma. Five of 759 cases were microinvasive (invasive focus less than $1 \mathrm{~mm}$ in maximum size in a predominantly intraepithelial lesion); three of these five cases were multifocal, whereas the other two were unifocal. Of the 365 cases of infiltrating duct carcinoma not otherwise specified that were graded, 104 were grade 1, 137 were grade 2, and 124 were grade 3 . Among the 93 with lymph nodes available for assessment, 61 (66\%) cases had axillary metastases. Forty of the women with axillary node metastases also had distant metastases. The most common distant metastatic sites were lung, adrenal glands, and bone. In addition, there were 19 examples of metastases to the breast that were documented. Of these, 58\% (11/19) were cutaneous melanomas, and 21\% (4/19), 10\% (2/19), and $10 \%(2 / 19)$ represented carcinomas from the prostate, lung, and larynx, respectively.

Table 1 Distribution of the various histologic subtypes in 778 invasive carcinomas involving the male breast

\begin{tabular}{|c|c|c|}
\hline Histologic subtype & $\begin{array}{l}\text { Number } \\
\text { of cases }\end{array}$ & Percentage \\
\hline $\begin{array}{l}\text { Infiltrating duct carcinoma not otherwise } \\
\text { specified, including }\end{array}$ & 643 & 84.7 \\
\hline Carcinoma associated with Paget's disease & 34 & \\
\hline Carcinoma with prominent apocrine features & 17 & \\
\hline Carcinoma with medullary features & 4 & \\
\hline Carcinoma with osteoclast-like giant cells & 3 & \\
\hline Carcinoma with focal signet rings & 2 & \\
\hline Carcinoma with focal clear cells & 2 & \\
\hline Pleomorphic carcinoma & 2 & \\
\hline $\begin{array}{l}\text { Carcinoma with no notable distinctive } \\
\text { features }\end{array}$ & 579 & \\
\hline $\begin{array}{l}\text { Papillary intraductal carcinoma with } \\
\text { invasion in the form of infiltrating duct } \\
\text { carcinoma }\end{array}$ & 34 & 4.48 \\
\hline $\begin{array}{l}\text { Mixed infiltrating duct and mucinous } \\
\text { carcinoma }\end{array}$ & 26 & 3.4 \\
\hline Pure mucinous carcinoma & 21 & 2.8 \\
\hline Adenoid cystic carcinoma & 8 & 1.05 \\
\hline Tubular carcinoma & 6 & 0.8 \\
\hline Small cell carcinoma & 6 & 0.8 \\
\hline Invasive lobular carcinoma & 3 & 0.39 \\
\hline Solid neuroendocrine carcinoma & 3 & 0.39 \\
\hline Mixed lobular and ductal carcinoma & 3 & 0.39 \\
\hline $\begin{array}{l}\text { Adenocarcinoma with spindle cell } \\
\text { metaplasia }\end{array}$ & 2 & 0.26 \\
\hline $\begin{array}{l}\text { Pure signet ring carcinoma (no in situ } \\
\text { component) }\end{array}$ & 1 & 0.13 \\
\hline Invasive cribriform carcinoma & 1 & 0.13 \\
\hline Secretory carcinoma & 1 & 0.13 \\
\hline Squamous cell carcinoma & 1 & 0.13 \\
\hline Total & 759 & 100 \\
\hline Metastatic lesions & 19 & \\
\hline Final total & 778 & \\
\hline
\end{tabular}

${ }^{\mathrm{a}}$ Subsets included for information only (not WHO categories) 

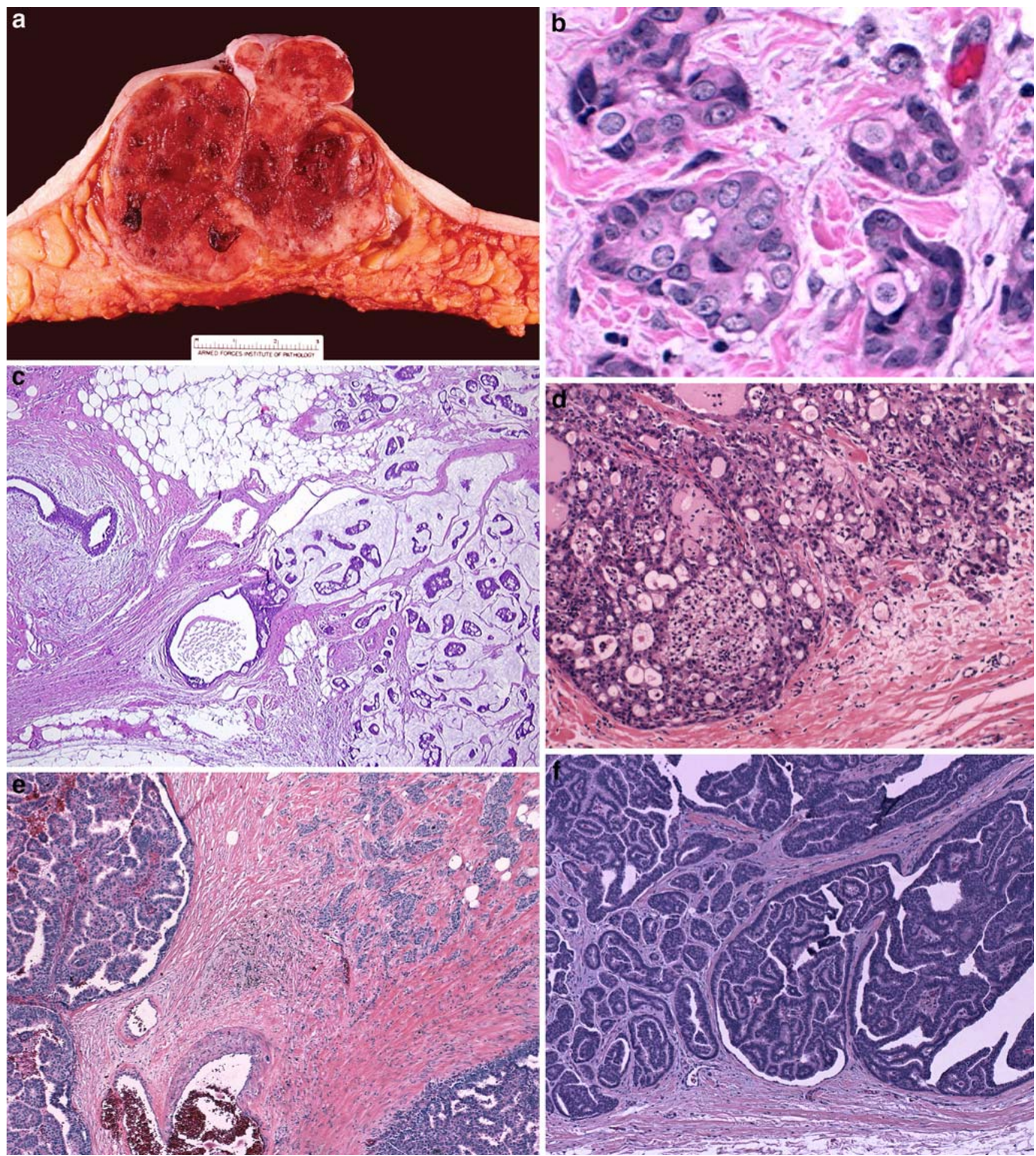

Fig. 1 Representative pathologic images of the various histologic subtypes. a and $\mathbf{b}$ Gross and microscopic images of infiltrating duct carcinoma, the most frequently encountered histologic subtype (b original magnification $\times 160$ ). c A colloid (mucinous) carcinoma (right field) occurring in a gynecomastoid breast (left field) (original

magnification $\times 100$ ). $\mathbf{d}$ The single case of a secretory carcinoma was in a 9-year-old boy, the youngest patient in this series (original magnification $\times 140$ ). e and $\mathbf{f}$ Examples of papillary intraductal carcinoma with invasion in the form of infiltrating duct carcinoma [original magnifications: $\times 100(\mathbf{e}), \times 120(\mathbf{f})]$ 


\section{Discussion}

The frequency, distribution, and morphologic spectrum of the various histologic subtypes of male breast cancer as compared with its female counterpart may provide a valuable insight into the etiology and/or pathogenesis of both. This was perhaps best illustrated in the study of ductal carcinoma in situ by Hittmair et al. [13]. The authors showed that in the male breast, papillary DCIS occurred with a much higher frequency ( $46 \%$ of pure lesions) than expected, while solid, micropapillary, and cribriform patterns occurred with a much lower frequency (22\% of pure DCIS combined). Notably, only 5 of 114 cases were of comedo-type DCIS and only 7 of 114 cases were considered high grade. The authors concluded that predominance of papillary patterns among intraepithelial male breast lesions is a reflection of the relative abundance of ducts and the poorly developed terminal-ductal lobular units in male breast. Given the rarity of true comedo DIN in male breast, the authors speculated that the fully developed lobular environment and the female type hormonal milieu may be a requirement for development of comedo DIN [13].

In this study, we investigated in detail the frequencies and distribution of the various histologic subtypes in a large data set of invasive carcinomas seen at a large tertiary center over a 40 -year period. Our findings suggest that invasive carcinoma of the male breast displays a morphologic spectrum and distribution of histologic subtypes that is comparable to invasive carcinoma of the female breast and that no specific histologic subtypes are notably over- or underrepresented with the exception of papillary and lobular variants.

Papillary intraductal carcinomas basically assumed an infiltrating duct carcinoma pattern once they invaded the stroma (Fig. 1e,f). A papillary component was present in 34 (4.5\%) of 759 cases, representing the second most common histologic subtype. These papillary carcinomas appeared to have invaded either through massive expansion and total disruption of ductal confines with typical invasive patterns at their periphery or only focally disrupted the duct wall and invaded the surrounding stroma as an infiltrating duct carcinoma. The latter represents approximately $2 \%$ [5] of female breast invasive carcinomas and appears overrepresented in males. In a large population-based study, Giordano et al. [7] reported that $2.6 \%$ of invasive malignancies in males were papillary carcinomas, as compared with $0.6 \%$ in females $(p<0.0001)$. However, the differences between males and females with respect to the frequencies of the other histologic subtypes were also statistically significant. The significance of the papillary histologic subtype or papillary architecture in male ductal carcinoma requires further investigation but is most probably related to the architecture of the male mammary duct system with dominance of larger ducts.
The possibility of metastases to the breast should be considered when evaluating breast masses particularly if there is a history of cancer elsewhere. Nineteen cases of carcinoma metastatic to the male breast were seen over this study period, representing $2.4 \%$ (19/778) of all nonhematopoietic or lymphoreticular malignancies. This is again a twofold increase comparable to the $1.2 \%$ reported in female breast malignancies over a 10-year period [11]. Of the 19 metastatic tumors, $58 \%(11 / 19)$ were cutaneous melanomas, and $21 \%(4 / 19), 10 \%(2 / 19)$, and $10 \%(2 / 19)$ represented carcinomas from the prostate, lung, and larynx, respectively. It is interesting to note that prostatic carcinoma, which has been the subject of most reports of carcinomas metastatic to the male breast [10], was not the most common metastatic tumor in this series. The number of metastatic tumors in this series is relatively small, which is a limitation in interpreting the distribution of originating sites. Nonetheless, in the investigation of metastatic tumors to the male breast of an unknown primary site, our findings provide additional data on some of the most likely sites.

This study also confirms the occurrence of lobular carcinoma in the male breast. Three cases of invasive lobular carcinoma, diagnosed purely on a morphologic basis, were present among 759 cases $(0.4 \%)$. Three additional cases of mixed lobular and ductal carcinoma were also diagnosed over this period $(0.4 \%)$. Joshi et al. [16] found one (4\%) lobular carcinoma out of 27 cases, while Goss et al. [8] found $4(1.9 \%)$ cases out of a total of 229 . In the series of Giordano et al. [7], lobular carcinomas constituted $1.5 \%$ for their male breast cancers. It is noteworthy that all of these cases were interpreted as lobular based on morphology without E-cadherin immunostain confirmation.

In summary, invasive carcinoma of the male breast appears to display a morphologic spectrum and distribution of histologic subtypes, which is comparable to invasive carcinoma of the female breast with some variation. As expected, lobular carcinoma is exceedingly rare but was encountered in this series. There appears to be a twofold increase in the frequency of invasive papillary carcinoma and metastatic cancers to the male breast as compared to published data in the female breast. Finally, the most common tumor metastatic to the male breast in this series was cutaneous melanoma.

Acknowledgement Ana M. Burga and Oluwole Fadare are equal contributors and coequal first authors.

\section{References}

1. American Cancer Society (2004) Cancer facts and figures 2004. American Cancer Society, Atlanta

2. Dawson PJ, Paine TM, Wolman SR (1992) Immunocytochemical characterization of male breast cancer. Mod Pathol 5:621-625 
3. de Perrot M, Deleaval J, Robert J, Spiliopoulos A (2000) Thirtyyear experience of surgery for breast carcinoma in men. Eur $\mathrm{J}$ Surg 166:929-931

4. Donegan WL, Redlich PN (1996) Breast cancer in men. Surg Clin North Am 76:343-363

5. Fisher ER, Palekar AS, Redmond C, Barton B, Fisher B (1980) Pathologic findings from the National Surgical Adjuvant Breast Project (protocol no. 4) VI. Invasive papillary cancer. Am J Clin Pathol 73:313-322

6. Fox SB, Day CA, Rogers S (1991) Lack of c-erbB-2 oncoprotein expression in male breast carcinoma. J Clin Pathol 44:960-961

7. Giordano SH, Cohen DS, Buzdar AU, Perkins G, Hortobagyi GN (2004) Breast carcinoma in men: a population-based study. Cancer 101:51-57

8. Goss PE, Reid C, Pintilie M, Lim R, Miller N (1999) Male breast carcinoma: a review of 229 patients who presented to the Princess Margaret Hospital during 40 years: 1955-1996. Cancer 85:629639

9. Gradishar W (2000) Male breast cancer. In: Harris J, Lippman M, Morrow M, Osborne C (eds) Diseases of the breast, 2nd ed. Williams \& Wilkins, Philadelphia, pp 661-667

10. Green LK, Klima M (1991) The use of immunohistochemistry in metastatic prostatic adenocarcinoma to the breast. Hum Pathol 22: 242-246

11. Hajdu S, Urban JA (1972) Cancers metastatic to the breast. Cancer 20:1691-1696

12. Heller KS, Rosen PP, Schottenfeld D, Ashikari R, Kinne DW (1978) Male breast cancer: a clinicopathologic study of 97 cases. Ann Surg 188:60-65

13. Hittmair AP, Lininger RA, Tavassoli FA (1998) Ductal carcinoma in situ (DCIS) in the male breast: a morphologic study of 84 cases of pure DCIS and 30 cases of DCIS associated with invasive carcinoma - a preliminary report. Cancer 15(83):2139-2149

14. Hodgson NC, Button JH, Franceschi D, Moffat FL, Livingstone AS (2004) Male breast cancer: is the incidence increasing? Ann Surg Oncol 11:751-775
15. Jepson AS, Fentiman IS (1998) Male breast cancer. Int J Clin Pract 52:571-576

16. Joshi MG, Lee AKC, Loda M, Camus MG, Peterson C, Heatley GJ, Hughes KS (1996) Male breast carcinoma: an evaluation of prognostic factors contributing to a poor outcome. Cancer 77 : 490-498

17. Landis SH, Murray T, Bolden S, Wingo PA (1999) Cancer statistics, 1999. CA Cancer J Clin 49:8-31

18. Meijer-van Gelder ME, Look MP, Bolt-de Vries J, Peters HA, Klijn JG, Foekens JA (2001) Clinical relevance of biologic factors in male breast cancer. Breast Cancer Res Treat 68:249-260

19. Norris HJ, Taylor HB (1969) Carcinoma of the male breast. Cancer 23:1428-1435

20. Ravandi-Kashani F, Hayes TG (1998) Male breast cancer: a review of the literature. Eur J Cancer 34:1341-1347

21. Rogers S, Day CA, Fox SB (1993) Expression of cathepsin D and estrogen receptor in male breast carcinoma. Hum Pathol 24:148151

22. Rudan I, Rudan N, Basic N, Basic V, Rudan D (1997) Differences between male and female breast cancer. II. Clinicopathologic features. Acta Med Croatica 51:129-133

23. Tavassoli FA, Devilee P (eds) (2003) World health organization classification of tumours. Pathology and genetics of tumours of the breast and female genital organs. IARC Press, Lyon

24. Temmim L, Luqmani YA, Jarallah M, Juma I, Mathew M (2001) Evaluation of prognostic factors in male breast cancer. Breast 10: $166-175$

25. Visfeldt J, Scheike O (1973) Male breast cancer. I. Histologic typing and grading of 187 Danish cases. Cancer 32:985-990

26. Wainwright JM (1927) Carcinoma of the male breast. Ann Surg 14:836-857

27. Weber-Chappuis K, Bieri-Burger S, Hurlimann J (1996) Comparison of prognostic markers detected by immunohistochemistry in male and female breast carcinomas. Eur J Cancer 32A:1686-1692

28. Weiss JR, Moysich KB, Swede H (2005) Epidemiology of male breast cancer. Cancer Epidemiol Biomark Prev 14:20-26 